Pesq. Vet. Bras. 36(9):851-856, setembro 2016 DOI: $10.1590 /$ S0100-736X2016000900010

\title{
Myocardial velocities obtained by pulsed tissue Doppler in English Cocker Spaniels with dilated cardiomyopathy and congestive heart failure ${ }^{1}$
}

\author{
Guilherme G. Pereira ${ }^{2 *}$, Guilherme T. Goldfeder², Fernanda L. Yamaki², Valéria M.C. \\ Oliveira $^{2}$ and Maria Helena M.A. Larsson ${ }^{2}$
}

\begin{abstract}
Pereira G.G., Goldfeder G.T., Yamaki F.L., Oliveira V.M.C. \& Larsson M.H.M.A. 2016. Myocardial velocities obtained by pulsed tissue Doppler in English Cocker Spaniels with dilated cardiomyopathy and congestive heart failure. Pesquisa Veterinária Brasileira 36(9):851-856. Departamento de Clínica Médica, Faculdade de Medicina Veterinária e Zootecnia, Universidade de São Paulo, Av. Prof. Orlando Marques de Paiva 87, São Paulo, SP 05508-900, Brazil. E-mail: ggpereira2002@yahoo.com.br

Dilated cardiomyopathy (DCM) is characterized by systolic myocardial dysfunction which is identified by low myocardial velocities obtained by pulsed tissue Doppler (PTD). However, increased preload is known to increase myocardial velocities which could overestimate myocardial function and turn dysfunction characterization into a challenge in dogs with DCM and congestive heart failure. To test the hypothesis that increased preload could hamper identification of low myocardial velocities in dogs with DCM and congestive heart failure the present study prospectively evaluated 32 English Cocker Spaniel dogs, being 16 with clinical DCM and 16 healthy for control purpose. The PTD analysis of regional velocities were performed in both longitudinal and radial myocardial displacements and systolic (Sm), early (Em) and late diastolic (Am) velocities were obtained in left ventricular free wall (LVFW) and interventricular septum (IVS). Peak radial subendocardial and subepicardial Sm velocities were lower in DCM group compared to control $(0.065 \pm 0.018$ vs. $0.102 \pm 0.020 \mathrm{~m} / \mathrm{s}$ and $0.059 \pm 0.014$ vs. $0.094 \pm 0.025 \mathrm{~m} / \mathrm{s}$ respectively; $\mathrm{p}<0.001)$. Peak longitudinal Sm velocities were lower in basal and medial portions of LVFW $(0.093 \pm 0.034$ vs. $0.155 \pm 0.034 \mathrm{~m} / \mathrm{s}$ and $0.091 \pm 0.033$ vs. $0.134 \pm 0.037 \mathrm{~m} / \mathrm{s}$ respectively; $\mathrm{p}<0.001$ ) and IVS $(0.063 \pm 0.021$ vs. $0.136 \pm 0.039$ and $0.066 \pm 0.026$ vs. $0.104 \pm 0.032 \mathrm{~m} / \mathrm{s}$ respectively; $\mathrm{p}<0.001)$. Most of diastolic velocities were not significantly different between groups, although advanced myocardial disease and dysfunction are expected in DCM group. Reduction in systolic basal and medial longitudinal myocardial velocities and in radial myocardial velocities was the most significant PTD findings. Increased preload did not represent a problem to evaluate systolic dysfunction by PTD in English Cocker Spaniels with DCM, but influence of preload on assessment of diastolic velocities should be better elucidated.
\end{abstract}

INDEX TERMS: Myocardial velocities, systolic function, diastolic function, dogs, cardiomyopathy, congestive heart failure, myocardial function.

RESUMO-- [Velocidades miocárdicas obtidas por meio de Doppler tecidual pulsátil em cães da raça Cocker Spaniel Inglês com cardiomiopatia dilatada e insuficiência

\footnotetext{
${ }^{1}$ Received on October 13, 2015.

Accepted for publication on April 14, 2016.

${ }^{2}$ Departamento de Clínica Médica, Faculdade de Medicina Veterinária e Zootecnia (FMVZ), Universidade de São Paulo (USP), Av. Prof. Orlando Marques de Paiva 87, São Paulo, SP 05508-900, Brazil. *Corresponding author: ggpereira2002@yahoo.com.br
}

cardíaca congestiva.] A cardiomiopatia dilatada (CMD) é caracterizada por disfunção miocárdica sistólica, a qual pode ser identificada pelas baixas velocidades miocárdicas obtidas por meio de Doppler tecidual pulsátil (DTP). Contudo, sabe-se que a elevada pré-carga aumenta as velocidades miocárdicas, o que poderia superestimar a função miocárdica e tornar desafiadora a caracterização da disfunção nos cães com CMD e insuficiência cardíaca congestiva. Para testar a hipótese de que a elevada pré-carga pode mascarar a 
identificação de baixas velocidades miocárdicas nos cães com CMD e insuficiência cardíaca congestiva, o presente estudo avaliou prospectivamente 32 cães da raça Cocker Spaniel Inglês, sendo 16 com manifestações clínicas de CMD e 16 hígidos para efeito de grupo controle. A análise DTP das velocidades regionais foi realizada tanto no deslocamento miocárdico longitudinal quanto radial e foram obtidas as velocidades sistólica (Sm), diastólica inicial (Em) e tardia (Am) na parede livre do ventrículo esquerdo (PLVE) e no septo interventricular (SIV). Os valores de Sm radial subendocárdicos e subepicárdicos foram menores no grupo CMD em comparação com o grupo controle $(0,065 \pm 0,018$ vs. $0,102 \pm 0,020 \mathrm{~m} / \mathrm{s}$ e $0,059 \pm 0,014$ vs. $0,094 \pm 0,025 \mathrm{~m} / \mathrm{s}$, respectivamente; $\mathrm{p}<0,001)$. Os valores de $\mathrm{Sm}$ longitudinais foram menores nas porções basal e intermediária da parede do ventrículo esquerdo $(0,093 \pm 0,034$ vs. $0,155 \pm 0,034 \mathrm{~m} / \mathrm{s}$ e $0,091 \pm 0,033$ vs. $0,134 \pm 0,037 \mathrm{~m} / \mathrm{s}$, respectivamente; $\mathrm{p}<0,001)$ e do septo interventricular $(0,063 \pm 0,021$ vs. $0,136 \pm 0,039$ e $0,066 \pm 0,026$ vs. $0,104 \pm 0,032 \mathrm{~m} / \mathrm{s}$, respectivamente; $\mathrm{p}<0.001$ ). A maioria dos índices diastólicos não apresentou diferença significativa entre os grupos, apesar de a doença miocárdica avançada e a disfunção serem esperadas no grupo CMD. A redução nas velocidades sistólicas longitudinais nos segmentos basais e intermediários e nas velocidades radiais representaram os achados mais relevantes no estudo com DTP. Nos cães da raça Cocker Spaniel Inglês com CMD e insuficiência cardíaca congestiva a pré-carga elevada não representou empecilho para a avaliação da disfunção sistólica por meio de DTP, porém a influência da pré-carga na avaliação das velocidades diastólicas deve ser mais bem investigada.

TERMOS DE INDEXAÇ̃̃O: Velocidades miocárdicas, função sistólica, função diastólica, cães, cardiomiopatia, função miocárdica.

\section{INTRODUCTION}

Dilated cardiomyopathy (DCM) is one of the most common causes of heart disease in dogs, mainly in large and giant breeds, male dogs, and being more prevalent and strongly familial in certain breeds, such as Boxer, Doberman Pinscher and English Cocker Spaniel (Tidholm \& Jonsson 1997). DCM is characterized by ventricular myocardial failure, represented by systolic (reduced contractility) and diastolic (relaxation and distensibility abnormalities) dysfunction, which results in a higher systolic and diastolic volumes, and occurrence of arrhythmias, contributing to congestive heart failure and high risk of sudden death (Sisson et al. 1999, Meurs 2005). Diagnosis is easily obtained by conventional echocardiography in advanced disease and systolic dysfunction is usually the main feature of this condition (Dukes-McEwen et al. 2003). Recent studies about therapy in dogs with DCM focused on evaluation of systolic function as an indicator of positive outcome induced by investigated protocol (Oyama et al. 2007, Soares et al. 2010).

Tissue Doppler, a novel echocardiographic technique, allows quantification of myocardial movement by eliminating low frequency/high amplitude filter from ultrasonic device (Isaaz et al. 1986, McDicken et al. 1992). The velocity of myocardial displacement can be obtained by pulsed tissue Doppler (PTD) evaluation, which represents a valu- able tool for investigation of myocardial diseases (Mishiro et al. 1999). As PTD technique is easily obtained in any ultrasonic device by adjusting pulsed wave Doppler filters, its use could be very helpful on clinical routine. Both radial and longitudinal displacements, represented by transversal and longitudinal fibers, respectively, are evaluated by this method, providing additional information when compared to conventional echocardiography. Systolic myocardial dysfunction due to DCM is identified by low myocardial velocities obtained by PTD. However, increased preload is known to increase myocardial velocities (Meco \& Cirri 2010) which could overestimate myocardial function and turn dysfunction characterization into a challenge in dogs with DCM and congestive heart failure. This influence could be a concern when systolic function is used as indicator of beneficial response in previous and future studies about therapeutic strategies for DCM in dogs. The present study intends to test the hypothesis that increased preload could hamper identification of low myocardial velocities in dogs with DCM and congestive heart failure.

\section{MATERIALS AND METHODS}

English Cocker Spaniel dogs diagnosed with DCM (DCM group) were included in this study. Diagnosis was established at the Department of Cardiology of the Veterinary Hospital of Faculdade de Medicina Veterinária e Zootecnia, Universidade de São Paulo (FMVZ-USP), Brazil, based on clinical criteria and scoring system previously described (Dukes-McEwen et al. 2003). All dogs in DCM group were in functional class III of heart failure, according to the International Small Animal Cardiac Health Council (ISACHC) recommendations for classification of the stage of heart failure (Bonagura et al. 1995). Physical examination, including recordings of heart and respiratory rates, rectal temperature measurement, cardiopulmonary auscultation, pulse quality assessment, inspection of apparent mucosal membranes and palpation of superficial lymph nodes were performed. A thoracic radiographic evaluation by lateral and ventrodorsal views were performed in order to help staging the disease and to exclude concurrent pulmonary disorders. Electrocardiographic recordings, including standard 6-frontal plane and precordial leads, were obtained in all dogs as previously described (Tilley, 1995), for heart rate determination and investigation of bundle branch blocks and arrhythmias. Doppler ultrasonic indirect systolic blood pressure recordings were performed to exclude systemic hypertension as a cause of lower myocardial function according to previous recommendations (Brown et al. 2007). The same number of healthy dogs, randomized for sex and weight, were also evaluated and included (control group). Physical examination, conventional echocardiographic and electrocardiographic examinations, thoracic radiographic evaluation and indirect systolic arterial blood pressure were also obtained from dogs in control group. Additionally, complete blood count, serum biochemical analysis (alanine aminotransferase and alkaline phosphatase activities and creatinine/urea concentration), urinalysis, and ELISA test for Dirofilaria immitis, Borrelia burgdorferi and Ehrlichia canis, were assessed in both groups.

Conventional transthoracic echocardiography, with continuous ECG monitoring, was performed according to the Echocardiography Committee of the Specialty of Cardiology, American College of Veterinary Internal Medicine (Thomas et al. 1993). An ultrasonic unit (Vivid 7 Expert, General Electric ${ }^{\circledR}$ ) equipped with 1,5-4,0 MHz and 3-8 MHz phased-array transducers was used for this purpose. Animals were awake and gently restrained in left 
lateral recumbence for left parasternal views and in right lateral recumbence for right parasternal views. Aortic root (Ao) and left atrium (LA) diameter were obtained by 2D echocardiography, through a right parasternal short axis view, and thus LA to Ao ratio was calculated. Using M-mode echocardiography, in a right parasternal short-axis view, left ventricular end-diastolic and end-systolic diameters, septal and left ventricular free wall thickness in diastole and systole, mitral E-point to septal separation, right ventricular diastolic diameter and fractional shortening (FS) were obtained (Boon 2011). Left ventricular ejection fraction calculation was calculated by modified Simpson's method, as previously described (Wess et al. 2010). Conventional pulsed-wave Doppler evaluation was performed, through left parasternal apical long-axis views, in order to record atrioventricular valves inflow, left and right ventricular outflow, and abnormal (turbulent) flows. Mitral E (early inflow) and A (atrial contraction inflow) waves peak velocities, as well as E/A ratio were determined.

PTD was performed in all dogs from both groups (DCM and control), with the same ultrasonic device used for conventional echocardiography. Dogs were awake and gently restrained in lateral recumbence. Longitudinal myocardial function was investigated by PTD through a left parasternal apical four chamber view, with a sample volume ranging from 2.5 to $3.0 \mathrm{~mm}$ and placed in six different myocardial regions: basal (mitral annular), medial (papillary muscle level) and apical portions of left ventricular free wall (LVFW) and interventricular septum (IVS). Radial myocardial displacement was assessed by a right parasternal short-axis view, at the level of papillary muscles, with sample volume (ranged from $2.5-3.0 \mathrm{~mm}$ ) placed in endocardial and epicardial regions of LVFW myocardium. For each segment, peak myocardial velocities resulting from ventricular systole $(\mathrm{Sm})$, early ventricular filling (Em) and atrial contraction (Am) were determined. Five consecutive cardiac cycles, represented by five consecutive QRS complexes in the simultaneous electrocardiogram (ECG), were recorded, and measurements were obtained for each cardiac cycle. The value considered for each parameter evaluated was the mean of these five measurements.

Peak E wave velocity of mitral inflow (Ef) and peak Em velocity, obtained from LVFW displacement at the mitral annulus level, were recorded in early diastole, and Ef/Em ratio was determined, in order to determine a congestive status in dogs from DCM group (Nagueh et al. 1997).

The study protocol was reviewed and approved by the Ethic Committee in the Use of Animals of FMVZ-USP, in order to assure adequate animal care (protocol \#1230/2007).

Values obtained for parametric data are expressed as means and \pm standard deviation (SD). Kolmogorov-Smirnov test was employed to investigate Gaussian distribution hypothesis of quantitative variables. Differences in numerical variables (age, weight, myocardial velocities, heart rate and Ef/Em ratio) between both groups (DCM group and control group) were interrogated by unpaired Student's $t$-test if parametric, considering different standard deviations and Welch correction, when appropriated, and by Mann-Whitney $U$-test, for non-parametrical data. Pearson's correlation coefficient was employed in order to investigate influence of Ef/Em on myocardial velocities recorded. $P$ values $<0.05$ were considered statistically significant.

\section{RESULTS}

The study population included 32 English Cocker Spaniel dogs, being 16 in the control group and 16 in the DCM group. Eight male and eight female dogs were included in each group. Weight ranged from 10.8 to $15.2 \mathrm{~kg}$ (mean 12.5 $\mathrm{kg}, \mathrm{SD} \pm 1.25$ ) in the DCM group and from 10.9 to $15.4 \mathrm{~kg}$ (mean $12.8 \mathrm{~kg} ; \mathrm{SD} \pm 1.24$ ), and this difference was not sta- tistically significant. Mean age in DCM group was slightly higher as compared to control group (mean $8.25 \pm 2.89$ ver-

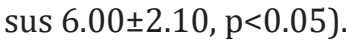

Heart rate obtained by electrocardiography ranged from 120 to 180 beats per minute (bpm) in DCM group (mean $147 \mathrm{bpm}$; SD \pm 23 ), and from 80 to $160 \mathrm{bpm}$ in control group (mean=103 bpm; SD \pm 19 ), and this difference was statistically significant $(\mathrm{p}<0.001)$.

All dogs included in both groups were in sinus rhythm. Most dogs in DCM group were in normal sinus rhythm (56.2\%, n=9), while sinus arrhythmia was the most common rhythm found in control group $(68.7 \%, \mathrm{n}=11)$. Another six (37.5\%) dogs from DCM group were in sinus tachycardia and five (31,2 \%) dogs in control group were in normal sinus rhythm. Six animals (27.2\%) in the DCM group showed isolated ventricular premature complexes.

Waves Sm, Em and Am were identified in all dogs (Fig.1 and 2). Peak systolic velocities were lower in the basal and medial portions of both LVFW and IVS in dogs with DCM, compared to findings of control group (Table 1 and 2). Also

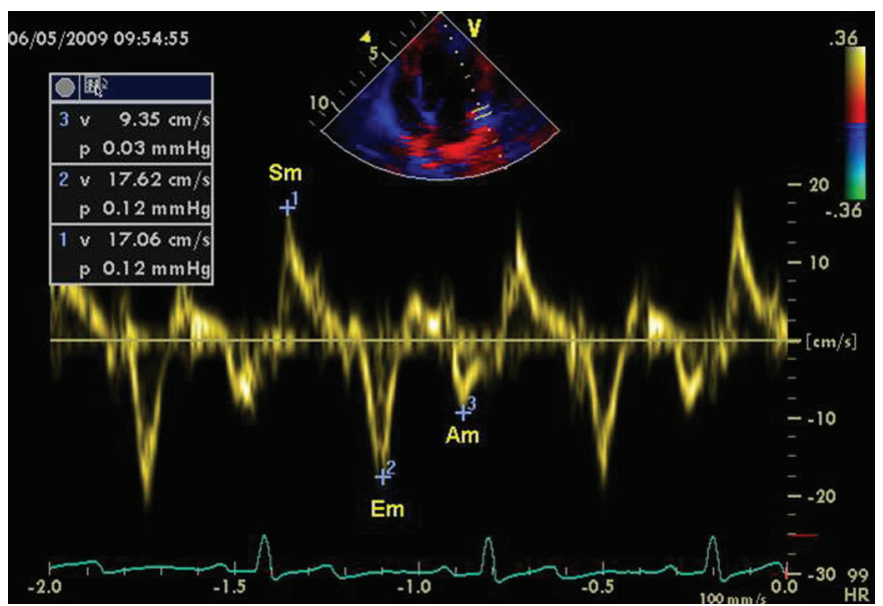

Fig.1. Pulsed tissue Doppler determination of longitudinal myocardial velocities in LVFW of a dog from control group. $\mathrm{Sm}$ = systolic myocardial wave; $E m$ = early myocardial diastolic wave; $A m$ = myocardial late (atrial) diastolic wave.

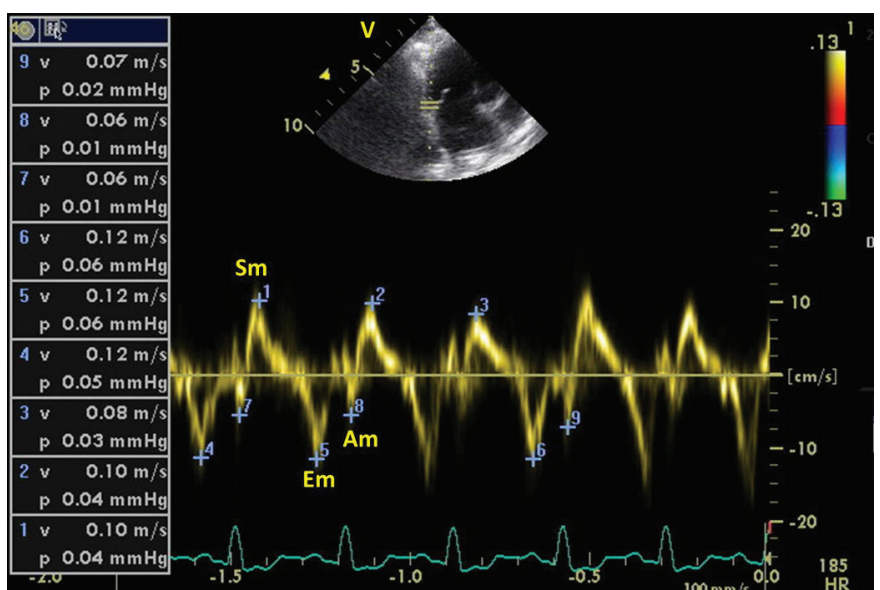

Fig.2. Pulsed tissue Doppler determination of longitudinal myocardial velocities in LVFW of a dog from DCM group. $\mathrm{Sm}=$ systolic myocardial wave; $E m$ = early myocardial diastolic wave; $A m=$ myocardial late (atrial) diastolic wave. 
systolic velocities recorded at the apical segment of IVS were lower in the DCM group. The E/A ratio < 1 was found in all segments of both LVFW and IVS in two dogs, in all seg-

Table 1. Means \pm SD of longitudinal myocardial velocities $(\mathrm{m} / \mathrm{s})$ obtained in interventricular septum of English Cocker Spaniels with dilated cardiomyopathy and healthy (control)

\begin{tabular}{lcc}
\hline & $D^{\mathrm{DCM}}(\mathrm{n}=16)$ & Control $(\mathrm{n}=16)$ \\
\hline $\mathrm{Sm}^{\mathrm{b}}$ (basal) $\S$ & $0.063 \pm 0.021$ & $0.136 \pm 0.039$ \\
$\mathrm{Em}^{\mathrm{c}}$ (basal) & $0.098 \pm 0.035$ & $0.096 \pm 0.025$ \\
$\mathrm{Am}^{\mathrm{d}}$ (basal) & $0.074 \pm 0.044$ & $0.068 \pm 0.017$ \\
$\mathrm{Em} /$ Am ratio (basal) & $1.588 \pm 0.678$ & $1.404 \pm 0.386$ \\
$\mathrm{Sm}$ (medial) $\S$ & $0.066 \pm 0.026$ & $0.104 \pm 0.032$ \\
Em (medial) & $0.095 \pm 0.044$ & $0.089 \pm 0.023$ \\
Am (medial) & $0.079 \pm 0.045$ & $0.061 \pm 0.020$ \\
Em/Am ratio (medial) & $1.353 \pm 0.708$ & $1.385 \pm 0.506$ \\
$\mathrm{Sm}$ (apical) & $0.064 \pm 0.032$ & $0.074 \pm 0.029$ \\
Em (apical) & $0.078 \pm 0.027$ & $0.061 \pm 0.021$ \\
Am (apical) & $0.060 \pm 0.025$ & $0.041 \pm 0.020$ \\
Em/Am ratio (apical) & $1.408 \pm 0.532$ & $1.498 \pm 0.517$
\end{tabular}

${ }^{a}$ DCM= dilated cardiomyopathy; ${ }^{\text {b }} \mathrm{Sm}=$ systolic myocardial wave; ${ }^{\mathrm{c}} \mathrm{Em}=$ early diastolic myocardial wave; ${ }^{\mathrm{d}} \mathrm{Am}=$ late diastolic myocardial wave. ${ }^{\#} \mathrm{p}<0.01 ;{ }^{\S} \mathrm{p}<0.001$.

Table 2. Means \pm SD of longitudinal myocardial velocities $(\mathrm{m} / \mathrm{s})$ obtained in left ventricular free wall of English Cocker Spaniels with dilated cardiomyopathy and healthy (control)

\begin{tabular}{lcc}
\hline & $\mathrm{DCM}^{\mathrm{a}}(\mathrm{n}=16)$ & Control $(\mathrm{n}=16)$ \\
\hline $\mathrm{Sm}^{\mathrm{b}}$ (basal) & & \\
$\mathrm{Em}^{\mathrm{c}}$ (basal) & $0.093 \pm 0.034$ & $0.155 \pm 0.034$ \\
$\mathrm{Am}^{\mathrm{d}}$ (basal) & $0.123 \pm 0.033$ & $0.134 \pm 0.032$ \\
$\mathrm{Em}^{\text {Am ratio (basal) }}$ & $0.073 \pm 0.033$ & $0.075 \pm 0.021$ \\
$\mathrm{Sm}$ (medial) & $1.830 \pm 0.685$ & $1.624 \pm 0.369$ \\
Em (medial) & $0.091 \pm 0.033$ & $0.134 \pm 0.037$ \\
Am (medial) & $0.152 \pm 0.051$ & $0.119 \pm 0.037$ \\
Em/Am ratio (medial) & $0.078 \pm 0.035$ & $0.070 \pm 0.021$ \\
Sm (apical) & $2.104 \pm 0.792$ & $1.737 \pm 0.530$ \\
Em (apical) & $0.076 \pm 0.033$ & $0.097 \pm 0.027$ \\
Am (apical) & $0.090 \pm 0.043$ & $0.076 \pm 0.024$ \\
Em/Am ratio (apical) & $0.056 \pm 0.020$ & $0.044 \pm 0.011$ \\
& $1.798 \pm 0.627$ & $1.730 \pm 0.481$
\end{tabular}

${ }^{a}$ DCM = dilated cardiomyopathy; ${ }^{\mathrm{b}} \mathrm{S} m$ = systolic myocardial wave; ${ }^{\mathrm{c}} \mathrm{Em}=$ early diastolic myocardial wave; ${ }^{\mathrm{d}} \mathrm{Am}=$ late diastolic myocardial wave; ${ }^{\#} \mathrm{p}<0.05 ;{ }^{\S} \mathrm{p}<0.001$

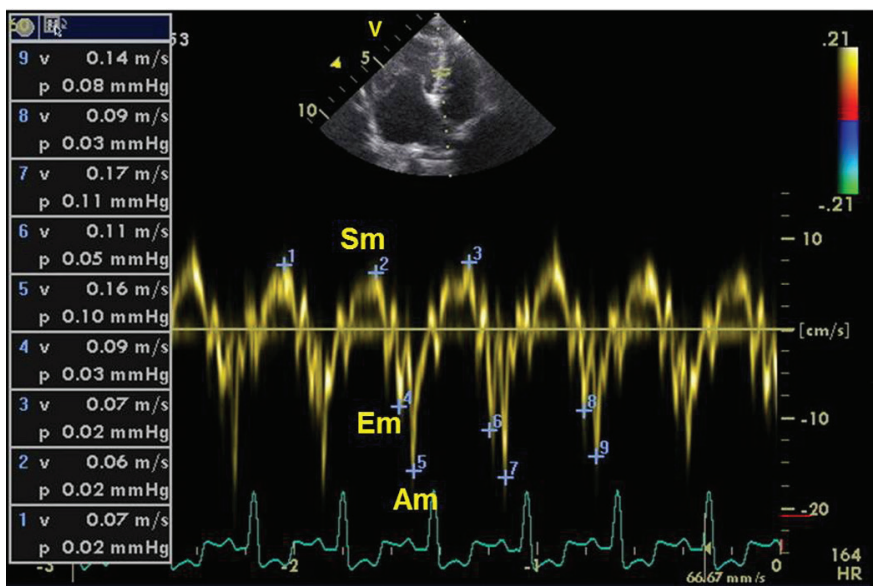

Fig.3. Pulsed tissue Doppler determination of longitudinal myocardial velocities in IVS of a dog from DCM group. Abnormal relaxation can be identified by Em velocity lower than Am velocity. $S m$ = systolic myocardial wave; $E m$ = early diastolic myocardial wave; $A m$ = late (atrial) diastolic myocardial wave.
Table 3. Means \pm SD of radial myocardial velocities $(\mathrm{m} / \mathrm{s})$ obtained in left ventricular free wall of English Cocker Spaniels with dilated cardiomyopathy and healthy (control)

\begin{tabular}{lcc}
\hline & $\mathrm{DCM}^{\mathrm{a}}(\mathrm{n}=16)$ & Control $(\mathrm{n}=16)$ \\
\hline $\mathrm{Sm}^{\mathrm{b}}(\mathrm{EDc}){ }^{\S}$ & $0.065 \pm 0.018$ & $0.102 \pm 0.020$ \\
$\mathrm{Em}^{\mathrm{d}}(\mathrm{ED})$ & $0.100 \pm 0.051$ & $0.109 \pm 0.061$ \\
$\mathrm{Am}^{\mathrm{e}}$ (ED) & $0.071 \pm 0.037$ & $0.078 \pm 0.015$ \\
Em/Am ratio (ED) & $1.628 \pm 0.781$ & $1.592 \pm 0.568$ \\
$\mathrm{Sm}(\mathrm{EPf})$ & $0.059 \pm 0.014$ & $0.094 \pm 0.025$ \\
Em (EP) & $0.086 \pm 0.031$ & $0.080 \pm 0.026$ \\
$\mathrm{Am}(\mathrm{EP})$ & $0.065 \pm 0.014$ & $0.055 \pm 0.019$ \\
Em/Am ratio (EP) & $1.623 \pm 0.843$ & $1.539 \pm 0.561$
\end{tabular}

${ }^{\mathrm{a}} \mathrm{DCM}=$ dilated cardiomyopathy; ${ }^{\mathrm{b}} \mathrm{Sm}=$ systolic myocardial wave; ${ }^{\mathrm{c}} \mathrm{ED}$ = subendocardial; ${ }^{\mathrm{d}} \mathrm{Em}=$ early diastolic myocardial wave; ${ }^{\mathrm{d}} \mathrm{Am}=$ late diastolic myocardial wave; ${ }^{\mathrm{f}} \mathrm{EP}=$ subepicardial; ${ }^{\S} \mathrm{p}<0,001$

Table 4. Means \pm SD of Ef wave velocities $(\mathrm{m} / \mathrm{s})$ and Ef/Em ratio obtained in left ventricular free wall of English Cocker Spaniels with dilated cardiomyopathy and healthy (control)

\begin{tabular}{lcc}
\hline & $\mathrm{DCM}^{\mathrm{a}}(\mathrm{n}=16)$ & Control $(\mathrm{n}=16)$ \\
\hline $\mathrm{Ef}^{\mathrm{b}}$ & $1.01 \pm 0.28$ & $0.77 \pm 0.13$ \\
$\mathrm{Ef}^{\mathrm{E}} \mathrm{Em}^{\mathrm{c}}$ ratio $^{\S}$ & $9.6 \pm 0.33$ & $6.21 \pm 0.26$
\end{tabular}

$\overline{{ }^{a} \mathrm{DCM}}=$ dilated cardiomyopathy; ${ }^{\mathrm{b}} \mathrm{Ef}=$ peak $\mathrm{E}$ wave mitral early diastolic flow; ${ }^{\mathrm{c}} \mathrm{Em}=$ early diastolic myocardial wave; ${ }^{\S} \mathrm{p}<0.001$.

ments of LVFW in one dog and in all segments of IVS in one dog. The same abnormality was found in IVS, only in basal and medial segments in one dog, and only in medial and apical segments on another one (Fig.3). All of the animals in control group had E/A ratio $>1$.

Peak subendocardial and subepicardial systolic radial velocities were significantly lower than values obtained in control group (Table 3). Peak E and A velocities, and E/A ratio were not different in both groups. Two dogs of DCM group had E/A ratio $<1$ in both subendocardial and subepicardial segments, and one in subendocardial segment. Results obtained demonstrated higher Ef/Em ratio in dogs from DCM group (Table 4).

\section{DISCUSSION}

To the authors' knowledge this is the first report of myocardial velocities evaluation by PTD in a population of English Cocker Spaniels. Although dogs were in a volume overload condition due to congestive heart failure, the present study demonstrated that myocardial systolic velocities were lower in DCM dogs and increased preload did not represent a clinically relevant concern. These findings could be helpful for interpretation of future studies investigating therapy strategies in dogs with DCM, mainly with inotropic drugs, even in the presence of congestive heart failure.

Once LVFW and IVS myocardial velocities are good indicators of systolic function in dogs (Hori et al. 2007), lower longitudinal peak Sm velocities of these segments as observed in this study could be explained by longitudinal myocardial systolic dysfunction in dogs with DCM. This regional dysfunction seemed to be more evident in basal and medial segments. Initial involvement of basal myocardial segments had been previously found in asymptomatic patients with DCM, suggesting being a feature of early ab- 
normality in DCM (Chetboul et al. 2004a, 2004b). The present study also found additional lower velocities in apical IVS segments and, considering that dogs included were in advanced disease, this finding could be an indicator of disease progression. Further studies are advocated in order to define prognostic value of this pattern of myocardial dysfunction and correlation with progressive myocardial failure. An abnormal systolic radial myocardial function, expressed as reduced peak $\mathrm{Sm}$ wave velocities of radial displacement at posterior wall of the left ventricle in DCM dogs, compared to control dogs, indicates radial myocardial fibers involvement. Such radial dysfunction was found both in subendocardial and subepicardial myocardial regions. Similar findings had been related in Golden Retrievers with Duchenne's-like muscular dystrophy (Chetboul et al. 2004b).

Except for peak Am velocities at apical interventricular septum, an absence of significant differences in diastolic velocities evaluated in both groups was surprisingly found, although diastolic dysfunction could be identified by PTD in some dogs from DCM group. Diastolic dysfunction identified by PTD indices had been demonstrated before, by color tissue Doppler imaging (TDI), in dogs with DCM (Chetboul et al. 2007). Differences in sensibility between both techniques should be considered for interpretation of these findings, once PTD velocities recorded online may be higher than reconstructed offline color-coded TDI signals (Yu et al. 2007). Also the population size could be not large enough to allow identification of statistical differences between groups. Previous studies that found abnormal diastolic velocities did not include English Cocker Spaniels and breed-specific variations need to be investigated. It is known that Doberman Pinschers with DCM have reduced diastolic myocardial velocities in the mitral annulus (O'Sullivan et al. 2007). Also lower subendocardial diastolic radial velocities and basal longitudinal diastolic velocities have been demonstrated in specific breeds (Chetboul et al. 2004a, 2004b). As the present study included only English Cocker Spaniels and there is no previous report describing PTD investigation of diastolic function in this breed, further breed related differences should be investigated.

Age-related influence also should be considered in this population, as mean age in DCM group was slightly higher. This limitation of the study could be minimized if dogs were also randomized by age, although the thin line between abnormal senescence and abnormal pathologic findings could be a challenge for the decision of including some old animals in a control group. A previous study had failed in finding age-related differences in systolic function of dogs using color-coded tissue Doppler (Chetboul et al. 2005), but early diastolic wave velocities were lower in left apex of elderly dogs. This source of influence should be better investigated when using PTD technique.

Most of previous studies were obtained in asymptomatic dogs, while the present report includes symptomatic dogs, in which preload influence is significantly higher and could have contributed to an increase in diastolic velocities even with myocardial diastolic failure. Higher Ef/Em ratio was found in DCM group which means an elevated left ventricular filling pressure and increased left atrial pressure (Oyama et al. 2004, Acil et al. 2005, Schober et al. 2008) in dogs with DCM, demonstrating that dogs in this group were really volume overloaded. Previous reports showed that a volume overload condition is supposed to influence diastolic waves obtained by tissue Doppler, increasing their velocities (Mendes et al. 2008, Tidholm et al. 2009, Schober et al. 2010). Those findings are more evident in a normal myocardial condition (Firstenberg et al. 2001, Nagueh et al. 2001, Quintard et al. 2012). The present study compared a population of dogs with normal preload and myocardial function with a population of dogs with increased preload and abnormal myocardial function and velocities were not quite different. Higher diastolic velocities were expected in DCM group because dogs were volume overloaded, but the diastolic myocardial failure could have neutralized this response. Additional studies investigating myocardial diastolic wave velocities in DCM dogs with or without congestive heart failure are recommended to investigate the preload influence in PTD diastolic waves of dogs with myocardial dysfunction and to elucidate if this preload influence is really significant in this population.

\section{CONCLUSIONS}

A reduction in systolic basal and medial myocardial longitudinal velocities and radial myocardial velocities represents the most significant pulsed tissue Doppler findings in English Cocker Spaniels with DCM and congestive heart failure, being PTD analysis a useful tool for assessment of systolic function despite of volume overload.

Investigation using PTD could provide reliable information in studies involving therapeutic strategies for improvement of myocardial function in dogs with congestive heart failure secondary to DCM.

Although increased preload did not represent a problem to diagnose systolic dysfunction in this group of dogs, its influence on assessment of diastolic velocities should be better elucidated.

Acknowledgements.- To Fundação de Amparo à Pesquisa do Estado de São Paulo (FAPESP) for financial support (protocol number 05/51442-7).

\section{REFERENCES}

Acil T., Wichter T., Stypmann J., Janssen F., Paul M., Grude M., Scheld H.H., Breithardt G. \& Bruch C. 2005. Prognostic value of tissue Doppler imaging in patients with chronic congestive heart failure. Int. J. Cardiol. 103:175-181.

Bonagura J.D., Bussadori C. \& Church D. 1995. Recommendations for the diagnosis of heart disease and the treatment of heart failure in small animals, p.469-490. In: Miller M.S. \& Tilley L.P. (Eds), Manual of Canine and Feline Cardiology. International Small Animal Cardiac Health Council. W.B. Saunders, Philadelphia.

Boon J.A. 2011. The two-dimensional echocardiographyc exam, p.37-100. In: Bonn J.A. (Ed.), Veterinary Echocardiography. Wiley-Blackwell, Iowa.

Brown S., Atkins C., Bagley R., Carr A., Cowgill L., Davidson M., Egner B., Elliot J., Henik R., Labato M., Littman M., Polzin D., Ross L., Snyder P. \& Stepien R. 2007. Guidelines for identification, evaluation, and management of systemic hypertension in dogs and cats. J. Vet. Intern. Med. 21:542-558

Chetboul V., Carlos Sampedrano C., Testault I. \& Pouchelon J.L. 2004a. Use 
of tissue Doppler imaging to confirm the diagnosis of dilated cardiomyopathy in a dog with equivocal echocardiographic findings. J. Am. Vet. Med. Assoc. 225:1877-1880.

Chetboul V., Carlos Sampedrano C., Blot S., Thibauld J.L., Escriou C., Tissier R., Retortillo J.L. \& Pouchelon J.L. 2004b. Tissue Doppler assessment of diastolic and systolic alterations of radial and longitudinal left ventricular motions in Golden Retrievers during the preclinical phase of cardiomyopathy associated with muscular dystrophy. Am. J. Vet. Res. 65:1335-1341.

Chetboul V., Carlos Sampedrano C., Gouni V., Concordet D., Lamour T., Ginesta J., Nicolle A.P., Pouchelon J.L. \& Lefebvre H.P. 2005. Quantitative assessment of regional right ventricular myocardial velocities in awake dogs by Doppler tissue imaging: repeatability, reproducibility, effect of body weight and breed and comparison with left ventricular myocardial velocities. J. Vet. Intern. Med. 19:837-844.

Chetboul V., Gouni V., Carlos Sampedrano C., Tissier R., Serres F. \& Pouchelon J.L. 2007. Assessment of regional systolic and diastolic myocardial functions using Tissue Doppler and Strain Imaging in dogs with dilated cardiomyopathy. J. Vet. Intern. Med. 21:719-739.

Dukes-McEwen J., Borgarelli M., Tidholm A., Vollmar A.C. \& Häggström J. 2003. Proposed guidelines for the diagnosis of canine idiopathic dilated cardiomyopathy. J. Vet. Cardiol. 5:7-19.

Firstenberg M.S., Greenberg N.L., Main M., Drinko J.K., Odabashian J.A., Thomas J.D. \& Garcia M.J. 2001. Determinants of diastolic myocardial tissue Doppler velocities: influences of relaxation and preload. J. Appl. Physiol. 90:299-307.

Hori Y., Sato S. \& Hoshi F. 2007. Assessment of longitudinal tissue Doppler imaging of the left ventricular septum and free wall as an indicator of left ventricular systolic function in dogs. Am. J. Vet. Res. 68:1051-1057.

Isaaz K., Cloez J.L., Ethevenot J.G., Danchin N. \& Pernot C. 1986. Analysis of the left ventricular wall motion by pulsed Doppler echocardiography: application to the assessment of myocardial function. J. Am. Coll. Cardiol. 7:228A.

McDicken W.N., Sutherland G.R., Moran C.M. \& Gordon L.N. 1992. Colour Doppler velocity imaging of the myocardium. Ultras. Med. Biol. 18:651654.

Meco M. \& Cirri S. 2010. The effects of load on systolic mitral annulus movements by tissue Doppler imaging in cardiac surgery patients. J. Cardiovasc. Surg. 51:277-281.

Mendes L., Ribeiras R., Adragão T., Lima S., Horta E., Reis C., Amaral T., Aguiar C., Gouveia R. \& Silva A. 2008. Load-independent parameters of diastolic and systolic function by speckle tracking and tissue Doppler in hemodialysis patients. Revta Port. Cardiol. 27:1011-1025.

Meurs K.M. 2005. Primary myocardial disease in the dog, p.1077-1081. In: Ettinger S.J. \& Feldman E.C. (Eds), Textbook of Veterinary Internal Medicine. 6th ed. Elsevier Saunders, St Louis.

Mishiro Y., Oki T., Yamada H., Wakatsuki T. \& Ito S. 1999. Evaluation of left ventricular contraction abnormalities in patients with dilated cardiomyopathy with the use of pulsed tissue Doppler imaging. J. Am. Soc. Echocardiogr. 13:913-920.

Nagueh S.F., Middleton K.J., Kopelen H.A., Zoghbi W.A. \& Quinones M. 1997. Doppler tissue imaging: a noninvasive technique for evaluation of left ventricular relaxation and estimation of filling pressures. J. Am. Coll. Cardiol. 30:1527-1533.

Nagueh S.F., Sun H., Kopelen H.A., Middleton K.J. \& Khoury D.S. 2001. Hemodynamics determinants of the mitral annulus diastolic velocities by tissue Doppler. J. Am. Coll. Cardiol. 37:278-285.

O'Sullivan M.L., O'Grady M.R. \& Minors S.L. 2007. Assesment of diastolic function by Doppler echocardiography in normal Doberman Pinschers and Doberman Pinschers with dilated cardiomiopathy. J. Vet. Intern. Med. 21:81-91.

Oyama M.A., Sisson D.D., Bulmer B.J. \& Constable P.D. 2004. Echocardiographic estimation of mean left atrial pressure in a canine model of acute mitral valve insufficiency. J. Vet. Intern. Med. 18:667-672.

Oyama M.A., Sisson D.D., Prosek R., Bulmer B.J., Luethy M.W. \& Fuentes V.L. 2007. Carvedilol in dogs with dilated cardiomyopathy. J. Vet. Intern. Med. 21:1272-1279.

Quintard H., Muller L., Philip I., Lena P. \& Ichai C. 2012. Influence of acute preload changes on mitral annulus velocity measured by tissue Doppler echocardiography in critically ill patients. J. Clin. Ultrasound. 40:419423.

Schober E.K., Bonagura J.D., Scansen B.A., Stern J.A. \& Ponzio N.M. 2008. Estimation of left ventricular filling pressure by use of Doppler echocardiography in healthy anesthetized dogs subjected to acute volume loading. Am. J. Vet. Res. 69:1034-1049.

Schober E.K., Hart T.M., Stern J.A., Li X., Samii V.F., Zekas L.J., Scansen B.A. \& Bonagura J.D. 2010. Detection of congestive heart failure in dogs by Doppler echocardiography. J. Vet. Intern. Med. 24:1358-1368.

Sisson D., O'Grady M.R. \& Calvert C.A. 1999. Myocardial diseases of dogs, p.581-619. In: Fox P.R., Sisson D. \& Moïse N.S. (Eds), Textbook of Canine and Feline Cardiology. 2nd ed. W.B. Saunders, Philadelphia.

Soares E.C., Pereira G.G., Petrus L.C., Santos A.L.F., Yamaki F.L. \& Larsson M.H.M.A. 2010. Survival and echocardiographic evaluation of dogs with idiopathic dilated cardiomyopathy treated with carvedilol. Arq. Bras. Med. Vet. Zoo. 62:555-563.

Thomas W.P., Gaber C.E., Jacobs G.J., Kaplan P.M., Lombard C.W., Moise N.S. \& Mases B.L. 1993. Recommendations for standards in transthoracic two-dimensional echocardiography in the dog and cat. Echocardiography Committee of the Specialty of Cardiology, American College of Veterinary Internal Medicine. J. Vet. Intern. Med. 7:247-252.

Tidholm A. \& Jonsson L. 1997. A retrospective study of canine dilated cardiomyopathy (189 cases). J. Am. Anim. Hosp. Assoc. 33:544-550.

Tidholm A., Ljungvall I., Höglund K., Westling A.B. \& Häggström J. 2009. Tissue Doppler and strain imaging in dogs with myxomatous mitral valve disease in different stages of congestive heart failure. J. Vet. Intern. Med. 23:1197-1207.

Tilley L.P. 1995. Essentials of Canine and Feline Electrocardiography. 3rd ed. Lea and Febiger, Pennsylvania. 484p.

Yu C.M., Sanderson J.E., Marwick T.H. \& Oh J.K. 2007. Tissue Doppler imaging. J. Am. Coll. Cardiol. 49:1903-1914.

Wess G., Mäurer J., Simak J. \& Hartmann K. 2010. Use of Simpson's method of disc to detect early echocardiographic changes in Doberman Pinschers with dilated cardiomyopathy. J. Vet. Intern. Med. 24:1069-1076. 